\title{
EXPLOITING THE COGNITIVE-PHYSICAL-EMOTIONAL INTERCONNECTION: MOTOWORDS AND THE DISTAL METHOD
}

\author{
Konstantinos G. Papageorgiou
}

Ionian University, Greece \& University of Athens, Greece

ORCID ii

Konstantinos Papageorgiou https://orcid.org/0000-0002-9289-5627

\begin{abstract}
Background: communication between trainer and athlete has been studied in terms offeedback, but not in terms of codifying information for instruction; here implications for cognition and cognitive skills are also discussed.

Purpose: to present a new tool, motowords, a tool for verbal codification between athlete and trainer that also provides a number of incidental benefits: it helps adjust the Degrees of Freedom \& Contextual Interference of a drill, it employs cognitive functions, fosters active participation of the athlete, and bridges the gap between serial and random practice. Moreover, we intend to theorize how the positive effects of motowords are multiplied when combined with drill-synthesis and drill-structure, in addition to differentiated (self)training, concepts that aim at increasing the ecological validity of training sessions.

Method: the theoretical background supporting the effectiveness of these tools is discussed.

Leads: to a broader vision about the important role of cognitive and emotional skills within a holistic context, aiming at developing "literate" individuals rather than just motor experts, both of which are at the very core of the Distal Method for expertise attainment.
\end{abstract}

Key words: motowords, prompting, perceptuomotor connection, motor learning, physical literacy

\section{INTRODUCTION}

The problem identified here is that of formal schooling and athletic education, both occupy the two extremes in a continuum. The formal school curriculum is largely context-insensitive/independent, unsituated, ersatz, non-indexical, practically unusable and in that sense, useless (Brown, Collins and Duguid, 1989). On the other side of the continuum, sports education has the complementary strengths and weaknesses: it exposes learners to purely practical situations, such as drills, with a poor cogni- tive or otherwise informational background other than often useless tautologies: "hit the ball harder"; "put the ball in"; "serve better"; "concentrate"; "try to remember"; etc. Can we reconcile or even exceed these two worlds in terms of synergy rather than just coexistence? It is my position, as is expressed in the present paper, that a more cognitive approach is needed in an athletic environment: by utilizing the vast cognitive resources of the individual, a better program may be developed that could, for example, lead to better learning of motor-skills and 
sequences. ${ }^{1}$

The tight connection between physical and cognitive domains, even emotions, extends to many different mechanisms and behaviours. Important cases for this relationship are included in the list of research findings presented here. To the author's knowledge, this kind of mini literature review has not been attempted before.

There are both behavioural and neurophysiological findings related to the motor-cognitive relationship. On the behavioural side, Schmidt $\&$ Wrisberg argue in favour of a motor-cognitive skill continuum, or "Dimension" (Schmidt and Wrisberg, 2008). This is also supported by the fact that cognitive, perceptual, and motor skills are acquired in essentially the same way; similarities include transfer specificity, learning rates and learning stages (Edwards, 2010). Edwards, instead of Schmidt \& Wrisberg's continuum, sees a Venn diagram. Priming affects both motor and cognitive tasks: from the classic Stroop-effect-related research (cf. MacLeod, 1991) to more recent research about the semantic- and auto-priming of motor skills, amongst others, the effect is found to be universal (Grossi, Maitra and Rice, 2007; Edwards, 2010). Representational re-description, Anette Karmiloff-Smith's model for the developed capacity of highly and specifically trained individuals to access and manipulate their memories at will (e.g. the ability to play variations of a musical piece at will, or start from e.g. the middle), refers to both declarative (e.g. mathematical skills) and procedural (e.g. a musical piece, a Kata) knowledge (Karmiloff-Smith, 1995).

The reverse has also been observed: there are cases of the physical exerting its effects on the cognitive through for example gestures, which are universal and facilitate thinking (Iverson and Goldin-Meadow, 1998; Schwartz and Heiser, 2006; Northrup and Iverson, 2015). Offline cognitive offloading to motor centers is another case where the physical and the cognitive domain work in concert; additionally, there are cases where the cognitive overrides the physical, such as in the placebo \& nocebo effect(s) (Weinberg and Gould, 1995; Wilmore and Costill, 2004; Magill, 2007). Feelings and emotions, such as those which occur from a "runner's high", affect decisions in both mental and motor domains (Goleman, 1995; Latash, 1998; Kano, Ito and Fukudo, 2011; Poletti et al., 2011; Carta, et al., 2013). Arts improve cognitive performance as well: Arts Foster Scientific Success: Avocations of Nobel, National Academy, Royal Society, and Sigma Xi Members is the title of the 2008 article by $\mathrm{R}$. Root-Bernstein and 14 more colleagues (RootBernstein, et al., 2008).

Closely related is the bibliography concerned with expertise, deliberate practice and attainment of high-performance. Perceptual, cognitive, and meta-cognitive skills, procedural knowledge and declarative knowledge were all found to be equally, if not very important in predicting and characterizing expert performance of athletes (Janelle and Hillman, 2003; Hodges, Starkes and MacMahom, 2006; Mann et al., 2007). The same broad principles of the expertise framework "should often (even if not always) apply to many other domains of human achievements, such as sports, chess, musical performance, and even various forms of leadership" (Simonton, 2013). Simonton, rather than a difference, sees a continuum from complex expressions of expertise to simple,

\footnotetext{
Simply put, skills refer to the technique, or to the quality of movement, and sequences to the succession of movements. For example, in yoga, skills are related to the correct body stance, while the succession of different asanas is the sequence. In theatre, articulation of each separate word, along with expressiveness are parts of the actor's skills; remembering the words of the play is, again, related to sequence learning. For the distinction between skill- and sequence-learning see also Krakauer and Shadmehr, 2006.
} 
the order being "roughly" as he presents in the same paragraph leadership, followed by creativity, musical performance, chess, and sports. Deliberate Practice, as well as the workload needed for expertise attainment, are like universal principles for both motor and cognitive expertise (Ericsson and Lehmann, 1996; Rossum, 2009). In "talent" development, the relative contribution of distinct parameters (as far as work is concerned) is common in the athletic and cognitive domain (Rossum, 2009). Reasons for dropping out are highly similar in arts, athletics, mathematics, music and science (Rossum, 2009 also citing Csikszentmihalyi, et al. 1993). Finally, knowledge structures"software" features and physical "hardware" features "consistently differentiate across skill in sport (Hodges, Starkes and MacMahom, 2006).

Since we are referring to "hardware", let us examine findings related to the neurosciences. The same neurophysiological principles support both perceptual-motor and intellectual skills acquisition (Rosenbaum et al., 2006). Encoding, consolidation and retrieval are processes involved, in this order, in memories about facts or motor skills (Kantak and Winstein, 2012). For example, exceptional worldclass level memorizers use a spatial learning strategy (Maguire et al., 2002). Working memory uses sensorimotor coding, as a wide range of phenomena reveal, e.g. overall pattern of data for sign language and speech is highly similar; findings from memory-impaired patients and brain imaging; "body schema", i.e., implicit connection between perception and action (Wilson, 2001). "For the Cerebellum, Movement and Thought Are Identical Control "Objects" (Vandervert, 2009): this section title in his article is quite enlightening about the interconnection of physical and cognitive at the functional level. The way infants move their limbs and torso in a world of informa- tion and physical forces determines the connections made in their brains and the biomechanical challenges they face, along with the solutions infants find that ultimately sculpt their brains (Thelen, 1998). Another finding comes from the development of language: it was possible only after the evolution of a powerful central motor capacity enabling hominids to voluntarily control their movements, unlike any other species (motor-modelling skill, or "mimesis" - Donald, Corballis and Lea, 1999).

The purpose of this study is to discuss how communication could be fostered with motowords, a verbal codifying methodology, since "Practice manipulations that require more cognitive effort were predicted to be more effective for motor learning compared to practice manipulations that require less cognitive effort” (Sherwood and Lee, 2003). “(...) language opens the way to a wider range of play (...). Even nonsense-words may help in this way, by providing symbolic aids to memory (...)." (Lewis, 1964). Such nonsense-words are the motowords discussed here.

\section{METHOD}

The theoretical background supporting the effectiveness of these tools is discussed. In what follows, we shall see the basic concepts that may support motowords: cognitive offloading, chunking, and sequence learning.

\section{Cognitive Off-Loading}

Cognitive off-loading is depending on the task a deliberate or unconscious process aiming at bypassing memorization and complex computations (Wilson, 2002). This is accomplished by utilizing the environment including ourselves; our bodies and even our cognition to off-load data. Examples of the second sort of off-loading is when using our fingers to count. The first sort of off-loading consists of an extended notion of a body-based, off-line cog- 
nition in which many sensorimotor functions appear to run "off-line" to assist in a variety of abstract mental tasks "as a means of representing information or drawing inferences" (Wilson, 2002) - such as the Buddhist monk problem (prove that a monk climbing on a mountain one day, will be on the same path at exactly the same point the next day and after half the time he needed to ascend).

Cognitive offloading may, for example, be in the form of a mnemonic, such as the name Roy G. Biv (red, orange, yellow, green, blue, indigo and violet: the colors of the rainbow). Similarly, motowords codify information about the drill being practised.

\section{Chunking}

Chunks were identified and defined as "memory symbols" as early as 1956 by A. Miller who also pointed out that seven is a characteristic number of the elements that comprise chunks, maybe less for inexperienced individuals (Sakai, Kitaguchi and Hikosaka, 2003) or much more for experts (Ericsson, Chase and Faloon, 1980). Chunks are perceptual or memory structures that bond more elementary units into larger organizations (Feltovich, Pretula and Ericsson, 2006). These writers also argue that chunks may be said to comprise the vast vocabulary experts develop over time, but due to their spontaneous nature which allows them to emerge as habits, they seem necessary in learning and retaining any kind of sequence. Thus, it should be of interest to assess whether chunks have operational significance i.e. how chunking may be best utilized as a verbal coding strategy to promote motor learning (see for example Sakai, Kitaguchi and Hikosaka, 2003). Chunking is a crucial element in the creation of motowords, since motowords would be more effective if they followed the limits posed by the encoding mechanisms of our short-term memory.
That is to say, the maximum length of motowords should be selected based on the level of the individual and might be based on trialand-error heuristics.

\section{Sequence Learning}

Sequence learning sometimes confused with skill learning (Krakauer and Shadmehr, 2006) is a process by which an individual is called to memorize a series of successive movements (more or less discrete ones) that are necessary to accomplish a task. These successions may be as few as the steps of a specific dance, to the thousands of successive fingers positions a piano player has to memorize to perform a concerto, or somewhere in between, such as the distinct movements that make up Katas in martial arts. Sequence learning refers only to the order of individual movements and not to the quality of movement per se, which is instead related to skill learning. However, it would appear that sequence learning produces skill learning as well, perhaps by introducing more stochastic perturbations in the distinct skills that together, in succession, form the sequence (Schöllhorn, et al., 2009).

A common problem for many practitioners is how to teach these sequences, or equally, movement-chunks that comprise the whole movement sequence. Part of the solution appears to benefit musicians and typewriters: they seem to be able to reproduce an enormous amount of movement combinations, not by remembering the movements themselves, but by connecting them somehow with notes or letters, thus using sounds as prompts. In other words, what is remembered appears to be the chunk segment labels (thus utilizing a form of cognitive off-loading) rather than motor chunks themselves. Stated another way, they use a strategy of self-priming for the motor task (sequence) at hand (Grossi, Maitra and 
Rice, 2007). Since the rapid execution of the whole chunk is dependent on the more conscious control of the chunk's first item (or element - Sakai, Kitaguchi and Hikosaka, 2003), motowords could provide a successful vehicle to control the chunk patterns.

Typists and musicians are not trained to reproduce the same set of movements, but rather the same result, oftentimes irrespective of the effector that will realize their mental representation, that is, one may use at will different movements to achieve the very same result (the effector specificity issue - Sakai, Kitaguchi and Hikosaka, 2003). Nevertheless, the question now arises: can there be a similar way to code movements and offload them into other cognitive sites at the executive level? This would significantly transform the way many complicated sequences are taught or trained.

\section{RESULTS}

\section{Motowords}

It is proposed here that this may be achieved by naming each distinct segment of the (chunk) sequence with a different syllable. No matter how many movements exist in a complicated sequence, they all derive from the combination of a much smaller repertoire of basic movement segments. By naming these distinct segments one could form a verbal/perceptual attractor basin for motor sequences (perceptuomotor coupling). In other words, a practitioner may become able to represent and automatically learn a much more complicated sequence, expressed as a series of motowords; one motoword for each chunk, one motosyllable for each chunk segment. Expressed in R. Schmidt's motor program model, motowords would help to "retrieve and parameterize the generalized motor program before each movement" (Schmidt and Wrisberg, 2008) helping learners to remember the procedural part of the motor skill by virtue of mental-verbal mediation (Schmidt and Wrisberg, 2008).

Learning motor sequence is important in many activities. In martial arts, dancing, surgery, machinery operation, and many sports manipulations long sequences of movements are demanded as a part of routines. In such activities, a significant amount of practice is devoted to merely learning and memorizing the sequence of actions. Moreover, for every new set of movements the learner must spend a considerable amount of time and effort not to forget it. Appropriately labelling chunk segments could diminish this effort during learning and even give some advantages during actual performance, for example when choking occurs or task complexity itself may hinder performance.

By expanding their working memories to Long Term Working Memories and by uniquely coding the stimuli expert performers are capable of performing tasks that are not achievable by untrained individuals. Tony Sargeant Sensei, a contemporary Aikido master, refers to advanced students who are required to repeat extremely long successions of movement by heart after seeing them just once. Such activities would greatly benefit from the introduction of task-specific chunk-labels - motowords.

Reduction of feedback (Edwards, 2010), an increase of Contextual Interference (Maslovat, et al., 2004), maximization of activity time (Baker, Cote and Abernethy, 2003) and increase in motivation could be other benefits from the implementation of motowords.

Motowords have already been used in martial sports, such as boxing, to quickly change sequences. For example, instead of instructing the athlete "hit one direct left punch, one direct right punch and one short left punch and an uppercut", the trainer may just use four one-syllable words and instruct "pow pow hook bam", 
even stressing the sound "bam" to indicate that it will be this hit the one to be stressed: "pow pow hook BAM".

In tennis, a sequence may be described by two motowords (two four-unit chunks) indicating a succession of eight shots. The sequence may be: "forehand drive, backhand slice, backhand drive, forehand winner // forehand volley, backhand volley, smash, smash", all these represented by the two motowords: "foslabaFO // vovasmasma" (each syllable describing one shot). The motosyllables used are always a matter of mutual agreement between the trainer and athlete. Experience shows that athletes need no more than a few sequencerepetitions with motowords before they get used to them.

Motowords in (drill) synthesis and structure

There is no distinction in the bibliography concerning drill-composition (synthesizing) and drill structuring - other than the first presentation at another paper of the author (Papageorgiou, 2019); however, their difference is crucial. The difference is analogous to piano playing and more specifically, to just "pressing" a series of keys just to improve the technical aspect of playing piano without any consideration for the melodies produced (synthesis) on one hand, and on the other hand, to interpreting a meaningful piece of music while maintaining a good technical form (structure).

In tennis, hitting a succession of balls in a drill with the aim to improve skill and technical form is drill synthesis. Drill synthesis is at best "form training" but not "(competitive) performance training” (Papageorgiou, 2019). That won't help to perform any better at tournaments unless it is followed by drill struc- turing: hitting a sequence of balls, but with a tactical purpose, be it to attack, to defend or just to win points. When doing drill synthesis simply counting points structures the drill, and the difference is immense. In drill structuring, one may use any type of tools, taken from sports psychology to theatre pedagogy so as to increase the ecological validity of the drill or focus on any specific performance parameter.

Motowords may easily be introduced into both drill synthesis and drill structure to adjust both the degrees of freedom and the contextual interference effect in many ways, two of which are described next.

\section{Motowords and differentiated (self)training}

The degrees of freedom (DOF) of a drill is related to the restrictions posed; the more the number of movements or otherwise allowed, the more the DOF is. Ceteris paribus, more DOF means more contextual interference, i.e. the motor control system has more information to process. Supposedly, the contextual interference phenomenon exerts its effects fully in random practice ${ }^{2}$ where the more the potential options, the more the DOF are. Serial practice is when the sequence of movements is known to the athlete before the drill starts and blocked practice (lowest DOF and contextual interference) is when the same skill is repeated continuously. ${ }^{3}$

Motowords may be said to provide an intermediate between serial and random practice - a significant contribution to available practice schedules. Using motowords, one may achieve any complexity they wish - especially combined with the notions of differentiated (self) training. So, there are three basic options regard-

\footnotetext{
2 a practice mode where the athlete does not know what comes next.

3 If a ceteris paribus clause is not in effect, then one may actually get increased contextual interference irrespective of DOF; for example, if the DOF remain the same but the athlete has to perform a mental task simultaneously, contextual interference increases.
} 
ing motowords and differentiated (self)training:

1. The athlete chooses the drill sequence by dictating motowords to the trainer.

2. The trainer chooses the drill sequence and differentiate based on the athlete's performance.

3. The athlete chooses the outcome of the drill with their actions.

The number of possible variations is bigger if every conceivable combination of these three cases is taken into account.

The introduction of exercises based on adaptability in general, and of self-training specifically, are important if we wish to maximize the ecological validity of our drills and successfully prepare athletes for competition. One cannot expect athletes to passively react to stimuli, then suddenly take initiatives, act and lead the action while competing. In every case, motowords may supplement the learning experience by making talking less relevant, while increasing the cognitive load. Motowords may even provide a good foundation for better planning of actions. So, the motowords selection should be based on mutual agreement and the various variations of output may be represented by e.g. the second motoword.

Example: after four shots in tennis (forehand drive, backhand slice, backhand drive, forehand winner) described by a 4-syllable motoword (foslabaFO), there could be a second four-syllable motoword (chosen from the trainer or the athlete) that would describe the scenario we have already seen: if the athlete decided to hit the $3 \mathrm{~d}$ ball crosscourt, the trainer must follow and feed a forehand volley, or else, if the athlete decides to hit a down the line winner, the trainer must follow the athlete's decision and feed a smash. The end moto-phrase would be:

foslabaFO // crovodasma

The second motoword could be split into two to make the alternative scenarios clearer: "crovo // dasma". Needless to say, all these must be constantly followed by arousal- and emotion-adjustment techniques.

\section{DISCUSSION}

Importance of cognition and emotions in sports

The tight link between the cognitive and the physical is especially stressed in the phrase: "imagery is often limited to the complexity of action available to the body" (Schwartz and Heiser, 2006), which supports the idea that traditional activities (yoga, aikido, tai-chi etc) should be implemented in general educational school programs. The specific link between higher cognitive skills and motor learning has already been presented regarding the development of prodigies through feedforward models (Vandervert, 2009).

Cognitive and physical domains are thought to be the two extremes of the same continuum and this is the reason some of their aspects are examined separately in literature as a result of the process of localization but that should not mean that they are really separate.

It is not even necessary to argue that both the cognitive functions utilized in a mathematical problem and the physical skills that make possible the performance of a skilled athletic manoeuvre stem from the Central Nervous System, which we have been wrongly led to believe has areas that work independently from each other due to the activation myth; in reality, "active" and "non-active" areas in the brain show very little difference in their "activation", maybe less than $2 \%$. Moreover, it is not very well known what "non-active" regions do, while according to more recent findings they are much more active than first thought. Additionally, it seems that the various regions both activated and less-activated constantly reconfigure to support task execution (Zuo, et al., 2018). With motor skills, it is necessary that 
physical adaptations take place, such as the improvement of proprioceptive acuity (Shmuelof, Krakauer and Mazzoni, 2012), but musculature alone, without CNS guidance is mere... meat. Throughout the present work, the universal relevance of physical and cognitive has been explicitly and implicitly admitted. Motowords is just one way to take advantage of this fact.

\section{Physical Practice and Higher Cognition}

A learning methodology such as the Distal Method (Papageorgiou, 2019) should incorporate tools such as motowords meaningfully (i.e., synthetically and structurally) in a broader vision about the development of an individual. This touches not only upon matters of better kinesiology but of "better" higher functions; even upon matters of education and pedagogy (cf. physical literacy - Pot, Whitehead and Durden-Myers, 2018).

Many researchers have identified a discrete bodily intelligence (Wallace and Maker, 2009) or bodily-kinesthetic intelligence (Gardner and Hatch, 1989; Gardner, 2006). Even though there is a strong case against the transfer of competency between discrete abilities already, from 1905 when Thorndike published his first study on the matter, there are cases where abilities do transfer, or more specifically there are abilities that affect each other and even are interconnected (Schwartz and Heiser, 2006), especially when they are taught with exactly this purpose in mind I would add. Higher cognition is important for sports performance (Janelle and Hillman, 2003; Hodges, Starkes and MacMahom, 2006). Can the opposite be the case? Can bodily intelligence positively affect cognition?

The eminent Japanese educator of the previous century, Jigoro Kano, developed Judo out of his study of a style of Ju Jutsu (Kito ryu). His goals for the children of Japan were 1) "to develop minds, bodies, and spirits in equal proportion, 2) increase patriotism and loyalty, especially to the Emperor, 3) teach public morality, and 4) increase physical strength and stamina, especially to make young men fitter for military service" (Wikipedia), and Judo was the means to achieve them. Kano conceived Judo mainly as a way to improve cognition and ethics. This is evident from his 1915 definition of Judo:

Judo is the way of the highest or most efficient use of both physical and mental energy. Through training in the attack and defence techniques of judo, the practitioner nurtures their physical and mental strength, and gradually embodies the essence of the Way of Judo. Thus, the ultimate objective of Judo discipline is to be utilized as a means to self-perfection, and thenceforth to make a positive contribution to society. (Wikipedia).

The aims of systems such as yoga, Aikido, Feldenkrais, meditation, Qi Gong, just to name a few, are similar, even though the processes and methods of each are unique and every system has some way to accomplish somewhat different goals. Newer systems such as Aikido and Feldenkreis are partly based on older systems, such as yoga and Qi Gong and incorporate many such influences.

Many studies point towards the positive effect of different types of physical practice on the cognitive functions (Posadzki, Parekh and Glass, 2010; Posadzki, Stöckl and Mucha, 2010; Zeidan et al., 2010). For example, Zeidan et al. 2010 found that even 4 days of mindless meditation practice enhances meta-awareness, executive functioning, and sustained attention improving related task performance in undergraduate students. Zachopoulou et al. (2006) designed and implemented a physical education program which successfully promoted creativity in 4 to 5-year-olds. (Zachopoulou, Trevlas and Konstadinidou, 2006). The variables that improved in this study included Divergent Thinking, Fluency, Self-esteem, 
Imagination, Flexibility, Independence, and Openness to Experience.

Edwards (2010) argues that there is growing evidence that intelligence and proficiency in motor skills, especially motor coordination, are significantly correlated. He points to large studies of pupils in both North America and Europe that link measures of intelligence and levels of motor coordination: "In one study, children with higher cognitive status were found more capable of carrying out complex motor tasks than were children of lower cognitive status". Schwartz \& Heiser 2006 go as far as to propose that one's thinking and problemsolving capacity "is often limited to the complexity of action available to the body".

When someone pushes you, there are over 20 reactions you may choose from in Judo, and much more in Aikido. When one doesn't even know if they will be pushed, pulled, hit (etc.), or a combination of the former, the reactions one may choose from are chaotic in number. The reaction, however, must be rapid, proper and fluid. There are preferred and less preferred reactions related both to the form of attack, and to environmental restrictions. From such examples, the existence of body-intelligence must be quite clear. One needs to be a kind of kinaesthetic genius to be able to smoothly use their body effectively in instances that demand fine-tuning of complex actions. Since people are not "brains in jars" and movement is a basic manifestation of our existence in a world of cognitive and physical information, both of which are processed as one identical object from structures such as the cerebellum (Vandervert, 2009), the development of movement intelligence per se is indeed a worthwhile goal (Thelen, 1998). Here, however, the additional benefits of physical to cognitive intelligence was briefly discussed.

Since physical practice is also associated with other benefits, and recent findings con- firm old assumptions about the positive cognitive effects of traditional practices, the inclusion of non-athletic physical practice programs in schools seems a positive, even necessary addition.

To close, Steven Pfeiffer in an article (which he was kind enough to include in a personal communication with me), Lessons learned from working with high-ability students (2012), presents three lessons learned throughout his career: "The three lessons are that identifying high-ability students is not an easy business, the development of talent requires more than ability, and success requires both head strengths and heart strengths" (Pfeiffer, 2012).

\section{CONCLUSION}

Motowords may be a valuable communication tool to combine with other tools in the creation of training sessions that serve any goal, from basic skill practice to more realistic competition-simulation. Motowords, apart from the way they might contribute to the every-day practice of athletes in a unique way, are also a positive step towards bridging the gap between physical training for the body and mental training for the mind; they are a step on a path we should take as a society towards a more holistic approach to sports.

\section{What Does This Article Add?}

- This article provides new tools for more effective practice sessions regarding practice schedules, mental training, communicating.

- It shows how practice sessions and developing motor expertise relates to higher cognitive functions and education.

Limitations of the article include the lack of experimental data directly elucidating the most effective applications motowords may have in tennis, in sports and elsewhere. However, this study introduces a novel paradigm and experiments may follow based on its assumptions. 


\section{REFERENCES}

Baker, J., Cote, J. and Abernethy, B. (2003). Sport-specific practice and the development of expert decision-making in team ball sports, Journal of applied sport psychology, (15), pp. 12-25.

Brown, J., Collins, A. and Duguid, P. (1989). Situated cognition and the culture of learning, Educational researcher, 18(1), pp. 32-42.

Carta M, G, Sancassiani F, Pippia V, Bhat K, M, Sardu C, Meloni L. (2013). Alexithymia is associated with delayed treatment seeking in acute myocardial infarction, Psychotherapy and psychosomatics. Karger Publishers, 82(3), pp. 190-2.

Donald, M., Corballis, M. C. and Lea, S. E. G. (1999). Preconditions for the evolution of protolanguages, in Corballis, M. C. and Lea, S. E. G. (eds) The Descent of Mind: Psychological Perspectives on Hominid Evolution. Oxford University Press, USA, p. 376.

Edwards, W. H. (2010). Motor Learning and Control from Theory to Practice. California: Wadsworth.

Ericsson, K. A., Chase, W. and Faloon, S. (1980). Acquisition of a memory skill, Science, 208(4448), pp. 1181-1182.

Ericsson, K. A. and Lehmann, A. C. (1996). Expert and exceptional performance: evidence of maximal adaptation to task constraints., $A n$ nual review of psychology, 47, pp. 273-305.

Feltovich, P. J., Pretula, M. J. and Ericsson, K. A. (2006). Studies of Expertise from Psychological Perspectives, in Ericsson, K. et al. (eds) The Cambridge handbook of expertise and expert performance. Cambridge University Press, pp. 41-68.

Gardner, H. (2006). Multiple Intelligences: New Horizons. Basic Books.

Gardner, H. and Hatch, T. (1989). Multiple Intelligences Go to School: Educational Implications of the Theory of Multiple Intelligences, Educational Researcher, 18(8), pp. 4-10.

Goleman, D. (1995). Emotional Intelli- gence: Why It Can Matter More Than IQ.

Grossi, J. A, Maitra, K. K. and Rice, M. S. (2007). Semantic priming of motor task performance in young adults: implications for occupational therapy, The American journal of occupational therapy: official publication of the American Occupational Therapy Association, 61(3), pp. 311-20.

Hodges, N. J., Starkes, J. L. and MacMahom, C. (2006). Expert Performance in Sport: A Cognitive Perspective, in Ericsson, K. et al. (eds) The Cambridge handbook of expertise and expert performance. Cambridge University Press, pp. 471-488.

Iverson, J. and Goldin-Meadow, S. (1998). Why people gesture when they speak, Nature, 396 (November).

Janelle, C. and Hillman, C. (2003). Expert Performance in Sport', in Ericsson, K. and JL, S. (eds) Expert Performance in Sports: Advances in Research on Sport Expertise.

Kano, M., Ito, M. and Fukudo, S. (2011). Neural substrates of decision making as measured with the Iowa Gambling Task in men with alexithymia., Psychosomatic medicine, 73(7), pp. 588-97.

Kantak, S. S. and Winstein, C. J. (2012). Learning-performance distinction and memory processes for motor skills: a focused review and perspective, Behavioural brain research. Elsevier B.V., 228(1), pp. 219-31.

Karmiloff-Smith, A. (1995). Beyond Modularity: A Developmental Perspective on Cognitive Science.

Krakauer, J. W. and Shadmehr, R. (2006). Consolidation of motor memory, Trends in neurosciences, 29(1), pp. 58-64.

Latash, L. P. (1998). Automation of movements: Challenges to the notions of the orienting reaction and memory, in Latash, M. L. (ed.) Progress in Motor Control: Bernstein's Traditions in Movement Studies. Human Kinetics, pp. 51-88. 
Lewis, M. M. (1964). Language, Thought and Personality: In Infancy and Childhood.

MacLeod, C. (1991). Half a Century of Research on the Stroop Effect: An Integrative Review, Psychological Bulletin, 109(2), pp. 163-203.

Magill, R. A. (2007). Motor learning and control: Concepts and applications. 8th edn. McGraw-Hill International Edition.

Maguire, E., Valentine, E., Wilding, J., Kapur, N. (2002). Routes to remembering: the brains behind superior memory, nature neuroscience, 6(1), pp. 90-5.

Mann, D., Williams A. M., Ward P., Janelle C. M. (2007) Perceptual-cognitive expertise in sport: a meta-analysis, Journal of sport \& exercise psychology, 29(4), pp. 457-78.

Maslovat, D., Chus, R., Lee, T. D., \& Franks, I. M. (2004). Contextual interference: single task versus multi-task learning, Motor control, 8(2), pp. 213-33.

Northrup, J. B. and Iverson, J. M. (2015). Vocal Coordination During Early Parent - Infant Interactions Predicts Language Outcome in Infant Siblings of Children with Autism Spectrum Disorder, Infancy, 20 (July), pp. 1-25.

Papageorgiou, K. G. (2019). The Distal Method: from psychomotor education to motor expertise, Journal of Physical Education and Sport, 19(1), pp. 633-644.

Pfeiffer, S. I. (2012). Lessons learned from working with high-ability students, Gifted Education International. SAGE Publications, 29(1), pp. 86-97.

Poletti, M., Frosini, D., Pagni, C., Lucetti, C., Del Dotto, P., Tognoni, G., Ceravolo, R., \& Bonuccelli, U. (2011). Alexithymia may modulate decision making in patients with de novo Parkinson's disease, Functional neurology, 26(3), pp. 127-31.

Posadzki, P., Parekh, S. and Glass, N. (2010). Yoga and qigong in the psychological prevention of mental health disorders: a conceptual synthesis, Chinese journal of integra- tive medicine, 16(1), pp. 80-6.

Posadzki, P., Stöckl,A. and Mucha, D. (2010).

Qi Gong exercises and Feldenkrais method from the perspective of Gestalt concept and humanistic psychology, Journal of bodywork and movement therapies, 14(3), pp. 227-33.

Pot, N., Whitehead, M. E. and DurdenMyers, E. J. (2018). Physical Literacy From Philosophy to Practice, Journal of Teaching in Physical Education. Human Kinetics, 37(3), pp. 246-251.

Root-Bernstein, R., Allen, L., Beach, L., Bhadula, R., Fast, J., Hosey, C., Kremkow, B., Lapp, J., Lonc, K., Pawelec, K., Podufaly, A., Russ, C., Tennant, L., Vrtis, E., \& Weinlander, S. (2008). Arts foster scientific success: Avocations of Nobel, National Academy, Royal Society, and Sigma Xi members. Journal of Psychology of Science and Technology, 1(2), 51-63. https://doi.org/10.1891/1939-7054.1.2.51.

Rosenbaum, D. A., Augustyn, J. S., Cohen, R. G., Jax, A. (2006). Perceptual-Motor Expertise, in Ericsson, K. et al. (eds) The Cambridge handbook of expertise and expert performance. Cambridge University Press, pp. 505-522.

Rossum, J. H. A. van (2009). Giftedness and Talent in Sport, in Shavinina, L. (ed.) International handbook on giftedness. Springer, pp. 751-792.

Sakai, K., Kitaguchi, K. and Hikosaka, O. (2003). Chunking during human visuomotor sequence learning, Experimental brain research. Experimentelle Hirnforschung. Expérimentation cérébrale, 152(2), pp. 229-42.

Schmidt, R. A. and Wrisberg, C. A. (2008). Motor Learning and Performance: A Situation-based Learning Approach. Edited by I. Champaign. Human Kinetics.

Schöllhorn, W. I., Mayer-Kress, G., Newell, K. M., \& Michelbrink, M. (2009). Time scales of adaptive behavior and motor learning in the presence of stochastic perturbations, $\mathrm{Hu}$ man Movement Science, 28(3), pp. 319-333.

Schwartz, D. L. and Heiser, J. (2006). Spa- 
tial Representations and Imagery in Learning, in Sawyer, R. K. (ed.) The Cambridge Handbook of the Learning Sciences. Cambridge: Cambridge University Press, pp. 283-298.

Sherwood, D. E. and Lee, T. D. (2003). Schema theory: critical review and implications for the role of cognition in a new theory of motor learning, Research quarterly for exercise and sport, 74(4), pp. 376-82.

Shmuelof, L., Krakauer, J. W. and Mazzoni, P. (2012). How is a motor skill learned? Change and invariance at the levels of task success and trajectory control, Journal of neurophysiology, 108(2), pp. 578-94.

Simonton, D. (2013). Creative performance, expertise acquisition, individual differences, and developmental antecedents: An integrative research agenda, Intelligence. Elsevier Inc.

Thelen, E. (1998). Bernstein's Legacy for motor development: How infants learn, in Latash, M. L. (ed.) Progress in Motor Control: Bernstein's Traditions in Movement Studies. Human Kinetics, pp. 267-287.

Vandervert, L. R. (2009). Working Memory, the Cognitive Functions of the Cerebellum and the Child Prodigy, in Shavinina, L. (ed.) International handbook on giftedness. Springer, pp. 295-318.

Wallace, B. and Maker, C. J. (2009). DISCOVER/TASC: An Approach to Teaching and Learning That Is Inclusive Yet Maximises Oppor- tunities for Differentiation According to Pupils' Needs, in Shavinina, L. (ed.) International handbook on giftedness. Springer, pp. 1113-1142.

Weinberg, R. S. and Gould, D. (1995). Foundations of sport and exercise psychology. USA: Human Kinetics.

Wilmore, J. H. and Costill, D. K. (2004). Physiology of sport an exercise. 3rd ed. Human Kinetics.

Wilson, M. (2001). The case for sensorimotor coding in working memory, Psychonomic bulletin \& review, 8(1), pp. 44-57.

Wilson, M. (2002). Six views of embodied cognition, Psychonomic bulletin \& review, 9(4), pp. 625-36.

Zachopoulou, E., Trevlas, E. and Konstadinidou, E. (2006). The design and implementation of a physical education program to promote children's creativity in the early years, International Journal of Early Years Education. Routledge, 14(3), pp. 279-294.

Zeidan, F., Johnson, S. K., Diamond, B. J., David, Z., \& Goolkasian, P. (2010). Mindfulness meditation improves cognition: evidence of brief mental training, Consciousness and cognition, 19(2), pp. 597-605.

Zuo, N., Yang, Z., Liu, Y., Li, J., \& Jiang, T. (2018). Both activated and less-activated regions identified by functional MRI reconfigure to support task executions, Brain and Behavior. John Wiley and Sons Ltd, 8(1).

\section{Corresponding author:}

\section{Konstantinos Papageorgiou}

Ionian University

Information Science \& Informatics

72, Ioannou Theotoki str. Corfu 49100, Greece

E-mail: cconstantinoss@gmail.com 